\title{
Cessation of severe chylothorax and chylous ascites in a newborn with trisomy 21 after whole blood pleurodesis: A
} case report

\author{
Sebastian Rützel ${ }^{1 *}$, Corinna Gebauer ${ }^{1}$, Ferdinand Pulzer ${ }^{1}$, Karen Geva Steinhoff ${ }^{2}$, Ulrich Thome ${ }^{1}$ and Matthias Knüpfer ${ }^{1}$ \\ ${ }^{1}$ Department of Neonatology, Hospital and Clinic for children and adolescents, University Hospital of Leipzig, Germany \\ ${ }^{2}$ Hospital and Clinic for nuclear medicine, University Hospital of Leipzig, Germany
}

\begin{abstract}
We present a case of a newborn with trisomy 21 and congenital lymphatic malformation leading to severe chylothorax and chylous ascites, which was successfully treated with autologous blood pleurodesis. Other established measures like adaptet enteral nutrition, parenteral nutrition, octreotide therapy and operative pleurodesis failed to decrease pleural fluid secretion beforehand.
\end{abstract}

The second interesting aspect of this case is the fact, that intragastrally administered methylene blue resulted in a profound staining of the complete body.

This is, to our knowledge, the fist surviving child of this constellation reported in the literature.

\section{Introduction}

Fluid collection in tissues, such as nuchal edema, is caused by abnormal development of lymphatic vessels and is a common feature in fetuses with trisomy 21 [1]. In most of the cases the amount of fluid declines spontaneously before birth [2]. In some patients generalized lymphatic malformation causes continuing chylothorax and chylous ascites and as a final result hydrops fetalis [3]. This constellation is usually associated with a poor prognosis [4].

Established conservative therapy of connatal chylothorax alongside tapping the fluid is feeding medium-chain triglyceride formula, parenteral nutrition or administration of octreotide [5,6]. If these measures fail, pleurodesis is necessary. It causes an inflammatory reaction which leads to adhesion of the pleural sheets. There are several possible options to achieve this intrapleural inflammatory reaction. In mild cases just tapping the fluid with intrapleural tubes causes such a reaction via physical irritation. The same principle is surgical pleurodesis. Another option is to inject chemical compounds such as cytostatic drugs, tetracycline, povidon-iodine or talcum in the pleural cavity [7]. Finally, also biological compounds like a low virulent streptococcus pyogenes strain (OK-432) or, as in this case blood, can have the same effect [8].

Methylene blue is therapeutically used for methemoglobinemia [9]. Besides this, it is an established dye for intravital staining [10].

\section{Patient presentation}

Herein we present a patient with Down syndrome and persistent severe chylothorax in combination with chylous ascites caused by lymphatic malformation.

The patient was born to a 34 year old gravida 2 para 1 woman by cesarean section at a gestational age of 31 4/7 weeks. Prenatally, trisomy 21 was diagnosed via amniocentesis. The 1700 gram weighing female neonate with Apgar-scores of 4 (1 min) and 6 (5 min) required immediate intubation and positive pressure ventilation as well as drainage of pleural fluid to achieve adequate postnatal gas exchange.

A congenital heart defect and other severe malformation were ruled out sonographically, connatal infection with cytomegalovirus, parvovirus b19 and varicella-zoster virus was ruled out serologically and via polymerase chain reaction prenatally.

Continuous drainage of pleural fluid and ascites was necessary owing to a high rate of pleural fluid secretion. The patient had to be mechanically ventilated over a period of 80 days with the final extubation at postnatal age of 104 days.

Chylothorax was diagnosed with analysis of pleural fluid which revealed a content of $1.8 \times 10^{9}$ leukocytes per liter with $95.2 \%$ lymphocytes, 19.4 gram per liter of protein and 1.63 millimole per liter triglycerides [11]. Lymphoscintigraphy showed normal lymphatic drainage in arms and legs to axillary and inguinal lymph nodes without any trace of abdominal or thoracic lymphatic drainage (Figure 1). After starting breast milk feeding, clouding of the pleural fluid was seen. Therefore, medium chain triglyceride formula was subsequently administered.

Correspondence to: Sebastian Rützel, University Hospital and Clinic for children and adolescents, Medical Center for Women and Children, University Hospital Leipzig, Liebigstr. 20a, 04103 Leipzig, Germany, Tel: +493419723585, Fax: +493419723579, E-mail: sebastian.ruetzel@medizin.uni-leipzig.de

Key words: blood pleurodesis, connatal nonimmune hydrops fetalis, lymphatic malformation, trisomy 21

Received: May 05, 2017; Accepted: June 09, 2017; Published: June 12, 2017 
A

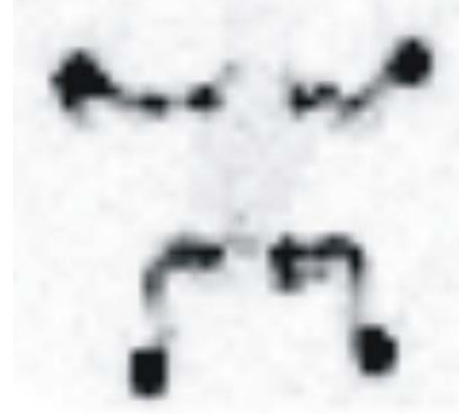

B

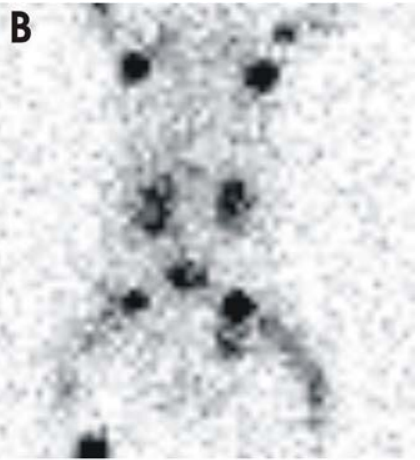

Figure 1. Lymphoscintigraphy after subcutaneous tetra-limb injection of $18 \mathrm{MBq}$ Tc-99m nanocolloid albumin; (A) Planar scan 1 hour p.i. showing a normal lymphatic drainage from the limbs into axillary and inguinal lymph nodes (B) Planar scan 20 hours p.i. without evidence of further abdominal or thoracic lymph flow.

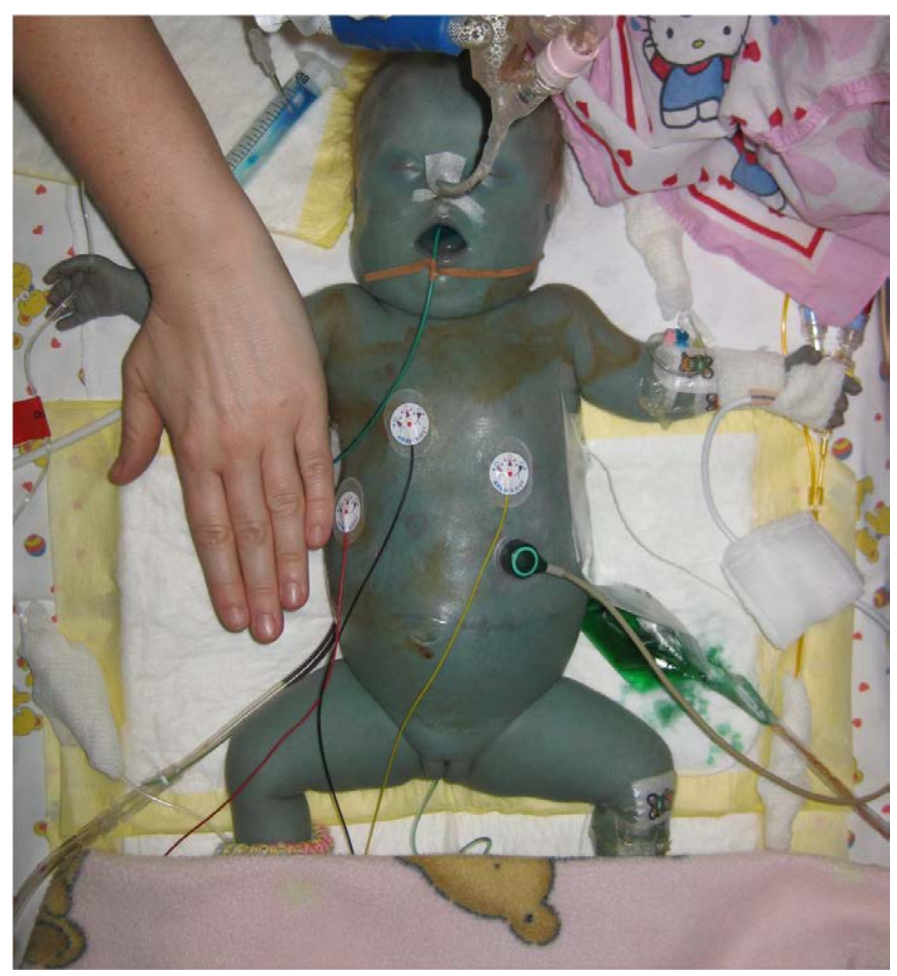

Figure 2. Generalized blue coloring of skin, ascites, gastric secretion and urine after administration of $15 \mathrm{mg}$ of methylene blue via nasogastric tube.

As effusions persisted, complete parenteral nutrition (over a time span of 61 days) and octreotide therapy were started. Despite intensified conservative therapy (dosing of octreotide was raised to a maximum of 700 micrograms per kilogram and day) the amount of tapped fluid from the pleural cavity remained high, so surgical pleurodesis with placement of fibrin sponges in the right pleural cavity was attempted on day 56. Despite central lymph vessels had not been detected during szintigraphy, $6 \mathrm{mg} / \mathrm{kg}$ of methylene blue were administered intraoperatively via nasogastric tube to determine if any circumscribed leaks into the pleural cavity were detectable. This was not the case. The dye instead produced a blue coloring of the complete skin and all body fluids (Figure 2). Haemolysis, methemoglobinemia, neurological symptoms or other side effects which are described in literature were not observed [12].

The surgical intervention brought only a temporary relief. When the

amount of drained fluid resurged to the preoperative level, autologous blood pleurodesis as an expanded access measure was performed after the parents gave written consent on day 64 of the patient's life: 10 milliliters of the patient's blood were drawn from a central line placed in the jugular vein, anticoagulated with 50 units of heparin and injected into the right pleural cavity via the pleural catheter. Drainage was discontinued for one hour and patient's position was alternated every 10 minutes to maximize the blood's distribution in the pleural cavity. After one hour the drainage was reopened. Fever up to $38.6^{\circ}$ Celsius and elevated C-reactive protein up to 19.7 milligram per liter occurred three hours after the procedure, blood-cultures remained sterile. Within two days after blood injection, the production of pleural fluid on the right side ceased completely. Chyle production in the left pleural cavity increased temporarily but subsequently ceased as well. Within seven days of the procedure both pleural drainages could be removed. One more single tap of the left pleural cavity had to be performed on day 23 after the procedure. Subsequently no more pleural effusions where seen.

Eight days after cessation of pleural effusions an increased amount of chylous ascites was observed, which had to be drained for 24 days until it vanished. The patient was discharged home on postnatal day 135 in good general condition. Subsequent neurological development was within the normal range of patients with trisomy 21 .

\section{Discussion}

In the presented case malfunction of central lymph vessels led to diffuse secretion of fluids into all body cavities. This presumption is supported by the fact that initial scintigraphy showed no central lymph vessels and enterally administered methylene blue distributed all over the body and was eliminated to a large extend via the pleural effusions rather than via the usual lymphatic drainage into the blood stream followed by renal excretion.

Because of possibly severe side effects of methylene blue administration, we appeal to enterally administer this drug only with caution in patients with abnormal lymphatic drainage.

In our patient the initially accomplished conservative measures to treat chylothorax and chylous ascites consisting of enteral nutrition with a medium-chain triglyceride formula, total parenteral nutrition and octreotide administration remained futile over 56 days, so surgically pleurodesis was attempted and failed as well. Therefore biological pleurodesis with blood instillation into one pleural cavity was performed. Blood pleurodesis was first used to treat recurrent air leaks when operative pleurodesis was no option but has also been described as another effective option in patients suffering from persistent fluid leaks [13]. Regarding newborn infants, one case was successfully treated with blood pleurodesis, although this patient had a normal karyotype and a different diagnosis (pulmonary congenital lymphangiectasia). He just developed pleural effusions postnatally after oral feeding was started [14].

In our case, effusions in the left pleural cavity definitely disappeared within two days after blood pleurodesis. The subsequent elevated C-reaktive protein and blood cultures remaining sterile indicate an inflammatory reaction. This inflammation might have been caused by an interaction between leucozytes in chyle and the instillated blood and led to tight adherence between pleural sheets. The close temporal connection between the inflammation and cessation of effusions suggests that blood pleurodesis was curative in this case. Possibly, the inflammation spread to the opposite pleura and the peritoneum after 
a short time lag. Alternatively, a spontaneous improvement of lymph flow developed at the same time unrelated to the blood pleurodesis. However, it appears unlikely that the close temporal relation occurred just by chance after such prolonged futile treatment efforts. The lymphatic fluid henceforth was drained in another direction. This is supported by the fact that the lymphatic drainage into the left pleural cavity and subsequently the abdomen increased when the right pleural cavity was gummed up.

Trisomy 21 with severe antenatally diagnosed pleural effusions is a rare but very severe disease [15]. To our knowledge, this patient is the first surviving newborn of this constellation who survived thanks to blood pleurodesis. We conclude that blood pleurodesis may be considered in patients with severe pleural effusions due to generalized lymphatic malformation as a valuable therapeutic option.

We obtained informed consent of the patient's parents to publish the patient's case including photography which allows the patient to be identified in a scientific publication.

\section{References}

1. Bellini C, Rutigliani M, Boccardo FM, Bonioli E, Campisi C, et al. (2009) Nuchal translucency and lymphatic system maldevelopment. J Perinat Med 37: 673-676. [Crossref]

2. Bronshtein E, Solt I, Bronshtein M, Gover A, Wolman I, et al. (2017) Detection Rate and Sonographic Signs of Trisomy 21 Fetuses at 14-17 Weeks of Gestation. Isr Med Assoc J 19: 8-12. [Crossref]

3. Ochiai M, Hikino S, Nakayama H, Ohga S, Taguchi T, et al. (2006) Nonimmune hydrops fetalis due to generalized lymphatic dysplasia in an infant with Robertsonian trisomy 21. Am J Perinatol 23: 63-6. [Crossref]
4. Gedikbasi A, Gul A, Sargin A, Ceylan Y (2007) Cystic hygroma and lymphangioma: associated findings, perinatal outcome and prognostic factors in live-born infants. Arch Gynecol Obstet 276: 491-8. [Crossref]

5. Kallanagowdar C, Craver RD. Neonatal pleural effusion. Spontaneous chylothorax in a newborn with trisomy 21. Arch Pathol Lab Med 2006; 130: e22-3. [Crossref]

6. Turan O, Canter B, Ergenekon E, Koç E, Atalay Y (2001) Chylothorax and respiratory distress in a newborn with trisomy 21. Eur J Pediatr 160: 744-745. [Crossref]

7. Brissaud O, Desfrere L, Mohsen R, Fayon M, Demarquez JL (2003) Congenital idiopathic chylothorax in neonates: chemical pleurodesis with povidone-iodine (Betadine). Arch Dis Child Fetal Neonatal Ed 88: F531-533. [Crossref]

8. Matsukuma E, Aoki Y, Sakai M, Kawamoto N, Watanabe H, et al. (2009) Treatment with OK-432 for persistent congenital chylothorax in newborn infants resistant to octreotide. J Pediatr Surg 44: e37-39. [Crossref]

9. Toker I, Yesilaras M, Tur FC, Toktas R (2016) Methemoglobinemia caused by dapsone overdose: Which treatment is best? Turk J Emerg Med 15: 182-184. [Crossref]

10. Jung M, Kiesslich R (1999) Chromoendoscopy and intravital staining techniques. Baillieres Best Pract Res Clin Gastroenterol 13: 11-19. [Crossref]

11. Soto-Martinez M, Massie J (2009) Chylothorax: diagnosis and management in children. Paediatr Respir Rev 10: 199-207. [Crossref]

12. Allegart K, Miserez M, Lerut T, Naulaers G, Vanhole C, et al. (2004) Methemoglobinemia and hemolysis after enteral administration of methylene blue in a preterm infant: relevance for pediatric surgeons. J Pediatr Surg 39: e35-e37. [Crossref]

13. Cobanoglu U, Melek M, Edirne Y (2009) Autologous blood pleurodesis: A good choice in patients with persistent air leak. Ann Thorac Med 4: 182-186. [Crossref]

14. Akcakus M, Koklu E, Bilgin M, Kurtoglu S, Altunay L, et al. (2007) Congenital pulmonary lymphangiectasia in a newborn: a response to autologous blood therapy. Neonatology 91: 256-259. [Crossref]

15. Miera O, Mildenberger E, van Baalen A, Fuhr N (2004) [Neonatal chylothorax with trisomy 21]. Z Geburtshilfe Neonatol 208: 29-31. [Crossref]

Copyright: (C2017 Rützel S. This is an open-access article distributed under the terms of the Creative Commons Attribution License, which permits unrestricted use, distribution, and reproduction in any medium, provided the original author and source are credited. 